\title{
A PARTICIPAÇÃo dOS VENDEdORES AMbULANTES de CARNe VERDE NA DEPOSIÇÃO DO GOVERNO ACCIOLY (FORTALEZA DO INÍCIO DO SÉCULO XX)
}

\author{
Mariana Dionísio de Andrade ${ }^{1}$ \\ Martônio Mont'Alverne Barreto Lima ${ }^{2}$ \\ Daniel Camurça Correia ${ }^{3}$
}

\section{RESUMO}

Busca-se com este artigo entender de que maneira os trabalhadores informais pobres, principalmente vendedores de carne verde (fresca), contribuíram para o movimento político que resultou na queda do governo Accioly, nas primeiras metades do século XX, na capital cearense. Com a perseguição contra a realização do trabalho informal, o número de revoltosos aumentava na cidade, até que, finalmente, dentro de uma composição coletiva, a multidão veio às ruas e exigiram a mudança de governo. O artigo possui uma abordagem teórica com base em revisão de literatura, especialmente a partir dos estudos de Rodolpho Theophilo e Raimundo Girão.

Palavras-chave: Vendedor Ambulante; Movimento Político; Trabalho Informal; Deposição de governo.

\footnotetext{
${ }^{1}$ Doutora em Ciência Política (Políticas Públicas) pela Universidade Federal de Pernambuco. Mestre em Direito Constitucional pela Universidade de Fortaleza - UNIFOR. Especialista em Direito Processual Civil pela UNIFOR. Professora do Curso de Pós-Graduação lato sensuem Direito Processual Civil e da disciplina Direito Processual Civil no Curso de Graduação em Direito na Universidade de Fortaleza. Formação em Leadership and Conflict Managementpela Stanford University. Formação em Métodos Quantitativos pela UERJ. Pesquisadora do Grupo Epistemologia e Método na Ciência Política Comparada (Cnpq/UFPE). Pesquisadora Líder do Projeto Processo Civil e Proteção da Pessoa nas Relações Privadas (Cnpq/UNIFOR). Pesquisadora do Laboratório de Ciências Criminais - LACRIM (Cnpq/UNIFOR). Advogada. Universidade de Fortaleza - UNIFOR. Fortaleza - CE; Brasil. ORCID iD: http://orcid.org/0000-0001-8698-9371 Lattes: http://lattes.cnpq.br/2375238086112583 E-mail: mariana.dionisio@gmail.com

${ }^{2}$ Pós-Doutor em Direito pela mesma Universidade de Frankfurt am Main. Doutor em Direito (Rechtswissenschaft) - pela Johann Wolfgang Goethe-Universität Frankfurt am Main, Mestre em Direito (Direito e Desenvolvimento) pela Universidade Federal do Ceará. Professor Titular do Programa de Doutorado em Direito Constitucional da Universidade de Fortaleza e Procurador do Município de Fortaleza. Foi Coordenador do Programa de PósGraduação em Direito/Mestrado e Doutorado em Direito Constitucional da Universidade de Fortaleza (19992006); Vice-Presidente da Ordem dos Advogados do Brasil - Secção do Ceará (2004-2005), Procurador-Geral do Município de Fortaleza (2006-2012) e Coordenador da Área de Direito na CAPES (2011-2014). Universidade de Fortaleza - UNIFOR. Fortaleza - CE; Brasol. ORCID iD: Lattes: E-mail: barreto@unifor.br

${ }^{3}$ Doutor em História Social (PUC/SP). Professor das disciplinas de Ciência Política e Filosofia do Direito (CCJ/UNIFOR). Líder do Grupo de Pesquisa em Filosofia do Direito (UNIFOR). Avaliador Nacional e Internacional do Conselho Nacional de Pesquisa e Pós-Graduação em Direito (CONPEDI). Universidade de Fortaleza - UNIFOR. Fortaleza -CE; Brasil. ORCID iD: https://orcid.org/0000-0002-8963-2180 Lattes Lattes: E-mail: daniel.camurca@unifor.br
} 


\section{INTRODUÇÃO}

Ao se pensar na deposição de um governo, geralmente, levam-se em consideração as dissonâncias políticas e filosóficas dos envolvidos. Porém, ao se questionar sobre o papel dos populares envolvidos nos levantes, observa-se que nem sempre os ditames filosóficos movem as pessoas.

Ao observar a realidade de Fortaleza, durante o início do século XX, nos acontecimentos que resultaram na deposição do governo Accioly, é possível entender o que moveu a população pobre e trabalhadora. Levando em consideração a forma como o poder público se relacionava com a venda de víveres na cidade, é possível entender como e porque a população apoiou decisivamente o movimento de deposição do governo.

Busca-se com este artigo analisar a forma como os trabalhadores informais, especialmente vendedores de carne verde (fresca), tentaram sobreviver e trabalhar em meio aos (des)mandos do governo. Em decorrência disso, entender a forma como os populares se organizaram para acelerar o levante a própria deposição no poder.

A metodologia de pesquisa foi baseada em registros de épocas, principalmente feitos pelo médico sanitarista Rodolpho Theophilo, assim como registros de memória de cronistas que viveram na cidade de Fortaleza, na primeira metade do século XX.

\section{VENDEDORES DE CARNE VERDE: ENTRE TRABALHO E CIDADANIA}

Na medida em que se aproximava o século XX, a comercialização de produtos alimentícios ficava cada vez mais difícil e arriscada na cidade de Fortaleza. Depois da instalação do Mercado de Ferro, as praças perdiam o status de feira livre da cidade. Médicos e sanitaristas cobravam da Intendência Municipal locais higienicamente adequados para a venda de carnes, verduras, leite, peixes e ovos. Todavia, de acordo com Rodolpho Theophilo, nenhum período foi pior para os trabalhadores das ruas do que a repressão exercida por Antonio Pinto Nogueira Accioly, no período de seu governo, durante o ano de 1904 até 1907 (PONTE, 1993). Afirma Rodolpho Theophilo que Accioly:

Um pouco compremettido açambarcou tudo que o município tinha que pudesse lhe dar lucros. Contratou a limpeza publica por cincoenta e quatro contos; arrematou os impostos dos mercados de fructas, hortalices, de caixas de miudezas, emfim ficou de posse do mercado publico, a excepção dos talhos de carne verde, que pertenciam a outros membros de sua família (THEOPHILO, 2001, p. 40). 
Deste modo, a família Accioly passou a controlar a comercialização de produtos alimentícios, impedindo que outras empresas, e, principalmente, os vendedores ambulantes, detivessem alguma possibilidade de sobrevivência neste setor da economia local. O Dr. Accioly receava ter um sucessor que não desse continuidade à hegemonia de poder exercida por sua família, especialmente no que dizia respeito à manutenção de influência sobre a economia e a arena política partidária. Para isto, colocava amigos íntimos e familiares dentro da política local. Não poderia ser diferente com Accioly Filho (MENEZES, 1938).

Além de muitos outros cargos - que segundo Theophilo (2001), nunca exerceu mas recebia os vencimentos - Accioly Filho era Procurador Fiscal do Estado. Com isso, tinha acesso às contas e arrecadações feitas pelo Presidente de Estado. Porém, segundo a documentação, este rapaz era um incompetente, no que realizasse. Acabou por se endividar, sendo obrigado a sugar mais ainda o dinheiro dos cofres públicos.

Mas, o que se quer ressaltar é o poderio econômico da família Accioly, especificamente dentro do Mercado Público. Além de controlar a venda de carne verde, que por si só já era uma considerável fatia do mercado, ainda mais por eles terem o monopólio da venda deste produto, também tinham acesso aos outros itens, principalmente, arrematando impostos.

Daí o motivo pelo qual, mais do que nunca, do controle sobre a venda informal de produtos perecíveis ser extinto. Os vendedores ambulantes de frutas, verduras, legumes e hortaliças não pagavam impostos, logo, não poderiam ser controlados pela família Accioly. Este fato iria resultar em variados desdobramentos - entre eles, a repressão exercida por policiais à paisana, pagos para eliminarem os vendedores (LINDENFELD, 1999).

Segundo o cronista, não foram poucas as atrocidades executadas pela família Accioly, porque monopolizavam todo tipo de comércio da cidade. Entretanto, foi com o controle da venda de carne verde que a população mais se revoltou. Os soldados eram assassinos contratados do interior para servirem ao governante, por conta disto, existia um considerável dispêndio com o corpo policial. Por outro lado, estes gozavam de absoluta liberdade de acesso dentro da cidade (THEOPHILO, 2001).

Tornou-se crítico o comércio informal de gêneros alimentícios em Fortaleza. Principalmente, pelo fato de alguns anos atrás a população ter sofrido perdas com a seca de 1900 . Os moradores da cidade reclamavam do preço da carne verde, que chegava a "custar um kilogramma de carne com ossos de 600 a 800 reis". O pior é que a carne geralmente era de péssima qualidade, revoltando ainda mais os populares. Outros produtos também tinham sofrido abusivo aumento nos preços, como "peixe de 1:200 a 2:000 por kilo; litro de feijão 400 reis; dito de milho 200 reis; dito de farinha 200 reis; carne de porco, kilo 1:400 reis; um ovo 100 reis; carne do sul kilo 1:400 reis", dentro do Mercado (THEOPHILO, 2001). 
Com estes preços é possível compreender o motivo pelo qual os vendedores ambulantes eram tão perseguidos. Nem todos tinham condições de comprar produtos a preços tão altos. A saída era esperar os vendedores de porta em porta passarem. Entretanto, como foi percebida a ausência desta fatia de compradores, os policiais foram mais uma vez convocados para "dar cabo" àquele comércio (THEOPHILO, 2001, p. 60-61).

A família Accioly tinha conhecimento do mercado informal e a proveniência da carne que era comercializada: Porangaba e Mecejana. Locais que permitiam mais facilidades em adquirir a carne verde pelos vendedores das ruas. O Sindicato da Carne, mantido pelo poder instituído, era equipado com soldados armados para impedirem o acesso de ambulantes no Mercado, bem como nas ruas e praças da cidade. Pois, "todas as madrugadas sahia uma patrulha a cavallo, de camisa e calça, revolver e faca a cinta e ia percorrer as estradas que desembocavam na cidade" (THEOPHILO, 2001, p. 62).

No caso de Fortaleza, os matadouros públicos não davam conta da demanda necessária para a subsistência urbana, o que obrigava o comércio a se abastecer em cidades vizinhas. Entretanto, estas carnes vindas de outras localidades não pertenciam aos domínios do Sr. Accioly, abrindo assim espaço para a concorrência.

Rodolpho Theophilo (2001), neste momento, fala na apreensão da carne e aprisionamento dos vendedores. Neste primeiro momento, todavia, nem sempre o problema era resolvido de maneira tão simples. Em alguns casos se fazia necessário usar uma pessoa como exemplo para os vendedores ambulantes restantes da cidade. Ou seja, a prática do assassinato era comum, a população tinha de ficar temerosa pela vida para obedecer aos policiais. O que, decerto, não acontecia.

Como está exposto no trabalho do autor, não era o suficiente patrulhar as ruas da cidade, mesmo durante dias e noites seguidas. A estratégia montada pela guarda cívica foi vigiar as estradas que davam acesso a Fortaleza. Isto, segundo a lógica destes homens, deveria conter o avanço de trabalhadores informais de carne verde dentro da capital cearense. Entretanto, isto nem sempre acontecia. Novas rotas de transporte eram organizadas, diferentes meios de entrar na cidade com os produtos foram elaborados. Isto é tanto que muito depois deste período o comércio "clandestino" de carne fresca continuou a existir (FOUCAULT, 1999).

O trecho de Theophilo que traz estas discussões ajuda a compreender que em dados momentos o discurso médico sanitário foi fundamental para a organização do controle do comércio informal de produtos perecíveis. Mas em outros, a questão econômica e de monopólio sobre a venda de carne, frutas, verduras, água e hortaliças ganharam mais visibilidade dentro da documentação.

Ao descrever as atrocidades cometidas pelos policiais a paisana, Theophilo (2001) não adentra nos perigos inerentes a uma carne que não foi inspecionada pelo médico competente, mas 
narra os conflitos, muitas vezes físicos, entre trabalhadores das ruas e guardas, os quais, a qualquer custo, lutavam pela sobrevivência.

Segundo o autor, eram tão comuns estas empreitadas dos "salteadores", que constantemente poder-se-ia vê-los andando pelos subúrbios da cidade rumo às estradas. Theophilo (2001) literalmente chama estes homens "pagos pelos cofres publicos" de caçadores, pois a intenção era emboscar a "presa", apossar-se de suas carnes, eliminando a vítima.

O que não quer dizer que a "vítima" não se defendesse. O embate físico era uma constante. A todo custo os vendedores ambulantes lutavam para trabalharem. Também andavam armados, e ainda mais quando foi decretado o "período de caça" pelo governo assim que estes guardas começaram a perambular pela cidade ${ }^{4}$.

Como foi colocado anteriormente, Rodolpho Theophilo conhecia bem esta teia de conflitos pelo fato de estar cotidianamente nos subúrbios de Fortaleza, tentando vacinar os populares contra a varíola. Para aqueles que praticamente não saiam de dentro da circunscrição urbana de Fortaleza, estes acontecimentos pouco chegavam aos ouvidos. Além do mais, quando os "salteadores" "passavam pelas ruas mais publicas da cidade, era para que [os ambulantes] os vissem e temessem", logo, nestes momentos não ocorriam embates diretos.

Dentro das principais ruas não poderia haver derramamento de sangue gratuito. Os guardas, muitas vezes, eram obrigados a esperarem o momento oportuno para aplicar o "bote". O que não quer dizer que o tempo todo os moradores do centro da cidade não pudessem - de seus sobrados presenciarem uma investida dos "malfeitores do governo".

Pelo contrário, para prenderem um vendedor ambulante até invadiam casas e residências, afinal, estavam protegidos pelo poder público - e estavam cientes disto. É tanto que invadiram a casa do próprio Theophilo.

Para melhor compreender os conflitos existentes entre os "salteadores" e os vendedores e vendedoras ambulantes de carne verde, na crônica de Theophilo (2001) é escrita uma passagem, na qual o próprio autor presenciou, em sua casa, a perseguição do governo aos trabalhadores das ruas.

Revelou Rodolpho Theophilo (2001) que numa manhã, decidiu não realizar a vacinação no subúrbio de Fortaleza, pela necessidade de fabricar mais vitelo para preparar vacinas contra a varíola. Quando menos esperava ouviu passos apressados dentro de sua casa. Ao dirigir-se ao encontro do invasor, o farmacêutico esbarra-se com uma "mulher do povo" perseguida por uma

\footnotetext{
${ }^{4}$ Afirma Rodolpho Theophilo que "encontrava-me todos os dias, quando andava no meu serviço de vaccinação pelos suburbios, com estes salteadores, pagos pelos cofres publicos, em desfilada pelas estradas dando caça aos vendedores de carne. (...) Não era só pelos suburbios que andavam estes malfeitores. Passavam pelas ruas mais publicas da cidade, para que os vissem e temessem. Perseguindo os pobres vendedores de carne, elles entravam em qualquer casa sem o menor respeito à família" (THEOPHILO, 2001, 62-3).
} 
pessoa "também do povo". Imediatamente, ao ver o dono da casa o homem, já dentro da sala, permaneceu inerte.

Segundo Theophilo (2001), de imediato ele percebeu do que se tratava: "a mulher era uma vendedora de carne e o homem um soldado disfarçado". Daí iniciou-se um interrogatório:

\begin{abstract}
Perguntei ao homem quem elle era. Disse-me ser um soldado da Guarda Civica e que andava tomando a carne que entrava de Porangaba, por ordem do Sr. Commandante. Respondi-lhe que elle não podia ser um agente do poder público por quanto não trazia as suas insígnias, que o trajo delle era de salteador, atacando de revolver e punhal os transeuntes nos caminhos para roubar. Que elle havia commettido um crime entrando em minha casa sem o meu consentimento, crime este previsto na Constituição. Que o azilo do cidadão era inviolável e que eu podia tel-o repellido a bala (THEOPHILO, 2001, p. 63).
\end{abstract}

Afirma o farmacêutico que o invasor pareceu não compreender o que dissera, e que, continuou a insistir na prisão da mulher. Irritando-se com a insistência do homem, Theophilo ordenou-o a retirar-se dali, levando consigo a bacia com grande quantidade de carne despejada próxima ao portão. O soldado saiu resmungando, principalmente, porque não conseguiu capturar a vendedora ambulante. De acordo com o autor, os "salteadores" não tinham critérios, adentravam nas residências das pessoas para conseguir a carne comercializada ilegalmente - segundo a família Accioly.

Theophilo (2001) estava em sua casa quando uma "mulher do povo" adentrou em sua residência em "tropel". Ao informar a situação que se passava, o farmacêutico revelou uma pérola para este trabalho: o fato de que dentro do universo de venda de carne verde conviviam homens e mulheres que disputavam o trabalho de comercialização informal.

De qualquer modo, Theophilo abriu espaço para discutir a participação das mulheres no universo de vendas de ruas da capital cearense. Ao entrar neste aspecto, o autor também permitiu adentrar no universo conflituoso destas mulheres com os guardas civis. Homens ou mulheres, adultos ou crianças, os "salteadores" escondiam-se pelas ruas da cidade na tentativa de apreendêlos. Obviamente que, no caso das mulheres, existiam interesses sexuais. Afinal de contas, o policial não queria sair da casa de Rodolpho Theophilo sem a "presa" (BARBOSA, 1999).

Tentando compreender o motivo pelo qual os soldados se empenhavam tanto no saque aos ambulantes, Theophilo interrogou um dos homens de Accioly:

Uma feita encontrei-me com um delles nas areias. Era um caboclo ainda novo. De boa cara, e que me pareceu não ser ainda criminoso. Perguntei-lhe se elle gostava de andar n'aquelle serviço odioso, tomando o que era de seus irmãos, homens tambem como elle, offendendo assim a lei e consciencia delle. Respondeu-me que achava isto muito mal feito, que fazia porque era mandado e que as mais das vezes fazia que não via os vendedores de carne. Perguntei-lhe o que elles faziam da carne que tomavam. Respondeu-me que tiravam a que precisavam para comer com suas familias, e o resto levavam para o Posto Policial, onde era ainda dividido 
e alguma que sobrava mandavam para o Azilo de Mendicidade (THEOPHILO, 2001, p. 65).

Primeiramente, observa-se, a partir da citação de Theophilo que as relações construídas entre os carregadores e vendedores ambulantes eram mais complexas do que pareciam. Constantemente os trabalhadores de ruas eram abordados pelos guardas cívicos. Em alguns casos, os guardas desdenhavam a presença dos trabalhadores ambulantes. Isto se dava por vários fatores. Pode ser analisado também o fato de que a presença dos vendedores das ruas era muito impactante, se a todo o momento os guardas perseguissem os vendedores para corrigir-lhes, prender-lhes e/ou agredir-lhes, o trabalho dos guardas não teria fim.

Além do mais, sabiam os guardas que de nada adiantaria todo esse trabalho. Tomavam a carne dos vendedores, no dia seguinte estes passavam com mais. Ou, simplesmente, se deparariam com outro vendedor. Pois, como aponta Theophilo (2001), a quantidade de carne era muito grande.

Ora, ao prenderem o vendedor ambulante de carne verde o guarda levava uma porção de carne para a sua família. O que sobrava, levavam para o Posto Policial. Ao chegarem, todos os policiais que traziam carne faziam uma nova distribuição, entre os presentes e ainda sobrava para doação ao Asilo de Mendicidade. Desta maneira, pode-se perceber que era muita carne! Ainda mais se levar em consideração que a maioria dos guardas que saiam em serviço voltava para o Posto carregando uma bacia quase cheia, diariamente.

Conseguiria estes homens consumir, com suas famílias, toda esta carne? Era um serviço infindável realizado pelos policiais. Mais uma questão: o abate não dependia diretamente dos vendedores, se faltasse um, outro poderia estar no matadouro, junto aos talhadores de carne para levá-la até Fortaleza. Deste modo, mesmo matando os vendedores, de muito pouco adiantaria. O policial à paisana, abordado por Theophilo compreendia isto.

Manter o controle sobre os vendedores de carne era uma prática que os policiais da cidade de Fortaleza sabiam que era muito difícil de ser concretizada. Por isto, que, em muitos momentos, os guardas não faziam esforço algum para a manutenção da ordem pública. Sabiam que aquele comércio não ia se extinguir, ainda mais por que sabiam que a população da cidade - tanto os vendedores, quanto os compradores, precisavam e dependiam da venda informal de carne fresca.

Entretanto, não se pode esquecer que em outros momentos os guardas entravam em conflito direto com os trabalhadores informais, concretizando disputas físicas, demarcando, diversas vezes, campos de atuações, de conflito e de resistência. Se estes policiais levavam esta quantidade de carne para o Posto Policial, isto significava dizer que diversos vendedores de carne foram apanhados, e a ordem era matá-los.

Daí a importância de terem agilidade diante da perseguição entre policial e vendedor. A mulher que entrou na casa de Rodolpho Theophilo teve sorte - e foi muito esperta - entrou na casa 
de um cidadão. Não que isto a protegesse, mas o policial, ao entrar, criou, na verdade, um ato de invasão, de intromissão a propriedade particular. O provedor estava em casa, garantiu, então, para aquela mulher do povo mais um dia de trabalho - e de vida.

Theophilo (2001) descobriu o desvio de dinheiro, ao conversar com um dos membros da sociedade do Syndicato das Carnes. O informante afirmou que era obrigado a repassar o dinheiro que chegava a sua mão para o commensal do Sr. Presidente de Estado e não ao Thesoureiro da Intendencia.

Com este dinheiro, Jose Accioly amortizou a dívida de seu irmão. Entretanto, ainda sobrariam quinhentos mil reis que eram destinados para o Sr Antonio Nogueira Pinto Accioly, o Presidente de Estado. Desta maneira, o dinheiro coletado pelo Syndicato das Carnes referente aos impostos do Mercado Público era desviado para os interesses privados da família.

\section{TRABALHO INFORMAL E REVOLTA ARMADA}

Em outra passagem de seu texto, Theophilo dá interessantes indícios sobre as diversificadas relações estabelecidas entre os populares e os policiais. Durante as passeatas ocorridas em prol de Franco Rabelo, em 21 de janeiro de 1912, foi percebida entre os populares a presença de "um policia á paisana”. Automaticamente, os populares o perseguiram pelo boulevard Duque de Caxias. "ouviram-se grande vozearia, tiros, pessôas a correr e a gritar: - soldado disfarçado!..." (THEOPHILO, 2001, p. 110).

Ao mesmo tempo em que o policial foi descoberto de seu disfarce, os populares começaram a atirar pelas ruas. Aquele início de ano trazia para dentro da cidade de Fortaleza um estado de tensão muito grande. A família Accioly estava, cada vez mais, controlando e dominando a cidade com punho de ferro. Os impostos mais caros, os alimentos mais raros e a repressão policial se fazendo presente nas ruas e nas casas das pessoas.

Para muitos, Franco Rabelo, apesar de ser pouco conhecido, era um nome cogitado para a sucessão presidencial. Para legitimar sua candidatura, diferentes categorias sociais, bem como pessoas de diferentes faixas etárias fizeram campanhas a seu favor. Dentre elas a Liga Infantil próRabelo, que desfilou no dia 21 de janeiro de 1912. Os aliados de Accioly, no intuito de desagregar as campanhas, enviaram guardas disfarçados. Todavia, foram descobertos (THEOPHILO, 2001).

Existia dentro da população um medo muito grande de acontecer uma emboscada, e os guardas assassinarem uma enorme quantidade pessoas. Porém, todos arriscavam seus pescoços. Ninguém poderia imaginar os resultados destes acontecimentos. Por esta razão, a polícia era temida e observada. Além do mais, as repressões diante dos populares se faziam constantes. Cada dia que 
se passava mais pessoas morriam. No entendimento de Theophilo, estes fatores fizeram com que a população pobre adquirisse "um faro admiravel para reconhecer um soldado por mais bem disfarçado que estivesse" (THEOPHILO, 2001).

Correndo em disparada pela Duque de Caxias, vendo que pouco adiantaria correr, o policial parou, voltou-se para os populares e sacou o punhal. A confusão era grande, muitos começaram a jogar pedras. No que isto acontecia, uma acertou-lhe a cabeça, derrubando o soldado ao chão. Ao tentar recobrar a consciência para se levantar, os populares "deram-lhe então bordoadas a duas mãos, até deixarem-no por morto". Imóvel, o corpo foi abandonado. Segundo Theophilo, "este infeliz falleceu no dia seguinte em consequencia dos ferimentos" (THEOPHILO, 2001).

Estavam vivas na memória dos populares as estratégias elaboradas pelos policiais para agarrarem, capturarem e até matarem os "criminosos". O povo sentia-se injustiçado, e queriam vingar-se. No início da década de 1910, o Estado era a família Accioly, mas, além de agredir os policiais em nome dos maus tratos geridos pelos parentes, os populares agrediram os policiais pelas suas experiências vividas e compartilhadas com estes. Experiências estas que estavam presentes na memória, no corpo, em suas casas, nos momentos de lazer e de trabalho.

Este dia, para além das práticas políticas organizadas pelas pessoas que ali participaram da manifestação pró-Rabelo, também efervesceram as disputas travadas pelos policiais, soldados e os populares. No final da passeata, ao terem se retirado pelo menos dois terços dos manifestantes, surgiram, na Praça do Ferreira, tanto do lado sudoeste quanto nordeste, "um piquete de cavallaria". O conflito era latente.

Os soldados pisotearam e mataram grande parte de crianças e adultos presentes, espalharamse pela praça e perseguiram a cavalo os fugitivos. Também era possível encontrar os corpos de alguns soldados do Batalhão de Segurança. Por todos os lados eram visíveis às lutas entre soldados e populares. Ao final do dia, encontravam-se nas ruas mulheres a chorarem a perda de maridos e filhos (THEOPHILO, 2001).

Conta Theophilo (2001, p. 120) que, no dia seguinte, a segunda-feira de 22 de janeiro, os populares, mais ainda os "patriotas", amanheceram cheios de "apprhensões, tristezas e sobresaltos". Ao mesmo passo que a cidade parecia morta, com o seu comércio - formal e informal fechado - a Praça do Ferreira estava ocupada pelos militares. "O esquadrão de cavallaria amanheceu postado na praça todo de mosquetão embalado". No Palácio, a situação parecia ser mais grave, havia mais de duzentos praças guardando o local. A Secretaria de Justiça foi transformada em quartel, lotada de soldados de polícia.

A família de Accioly tomou todas estas medidas para intimidar o povo, afinal de contas, alguns conflitos, com mortes, já tinham acontecido. José Accioly, filho do Presidente do Estado, 
insistia para seu pai "mandar a força publica debandar os grupos de arruaceiros que estavam perturbando o socego publico" (THEOPHILO, 2001, p.121).

"A sua unica preocupação era se conservar no poder fosse por que meios fosse" (THEOPHILO, 2001, p. 122). Os cargos de confiança estavam, geralmente, nas mãos de seus familiares. Por outro lado, tinha também confianças nas suas milícias. Isto é tanto que, a terça parte das rendas arrecadas pelo Estado eram gastas com as forças policiais da cidade, que chegavam ao número de oitocentos a mil réis.

E os soldados sabiam disto, porque a todo o momento tomavam para si práticas de repressão e controle sobre os populares, mesmo que para isto fosse necessário matar. Por isto se deu o acontecimento conflituoso entre estes soldados e os vendedores de carne verde, e entre os manifestantes, no dia 21 de janeiro de 1912, segundo o farmacêutico.

$\mathrm{Na}$ manhã do dia 22 de janeiro, os guardas, ainda pouco satisfeitos com a investida do domingo passado, se dirigiram até o Mercado Público, lá ocorreu um novo conflito. Todavia, os soldados foram espantados pelos vendedores, carregadores e manifestantes, que atiravam pedras. $\mathrm{O}$ Mercado fechou suas portas. Por conta disto, as quitandeiras recolheram seus tabuleiros na feira das frutas e hortaliças para fugirem da briga (THEOPHILO, 2001).

É interessante perceber que sempre foi muito positivo, para os populares, o fato das ruas da cidade de Fortaleza estar, normalmente, mal empedradas. Isto facilitava nas formas de defesas organizadas pelos trabalhadores ambulantes ou mesmo, no caso, para os manifestantes. Dificilmente estas pessoas citadas se utilizavam de armas de fogo - o que por outro lado não era impossível de acontecer - mas, pelo fato das pedras estarem sempre à disposição, o trabalho de carregar uma arma deixava de existir (BARBOSA, 1999).

$\mathrm{Na}$ tarde do dia 22, as forças do governo estavam, em sua maioria, concentradas nos arredores do Palácio. Para Accioly, a possibilidade do "populacho" invadir o prédio era uma questão de tempo. Ao mesmo passo, percebendo este encurralamento por parte das forças armadas, os “patriotas" trataram de sitiá-los. Presos dentro do Palácio do Governo, a família de Accioly se tornou alvo fácil, que com o tempo poderia se render aos manifestantes.

Estes, por outro lado, se fizeram de variados artifícios para acuarem ainda mais os escondidos. Armados, os populares se organizavam pela cidade de modo a se dividirem estrategicamente nos pontos altos e de visibilidade livre para o Palácio. Com isto, ficavam a atirar, muitas vezes tentando acertar a quem se aproximava da janela, outras para assustar as pessoas que estavam ali dentro. Por meio destas práticas de repressão psicológica, os populares amedrontavam a família de Accioly, incutindo nas suas cabeças, que a qualquer momento, poderia acontecer uma chacina. 
Ao mesmo tempo, alguns manifestantes se dirigiram para as estradas de Mecejana e Bemfica - as duas vias mais importantes de Fortaleza - para impedir a entrada de produtos alimentícios para o Palácio e a tentativa de fuga daqueles para fora da cidade. Por conta dos entrincheiramentos, a cidade ficou completamente paralisada.

Os talhadores de carne não abateram suas rezes naquele dia, os mercados de alimentos também não abriram suas portas. Nas ruas não era possível encontrar um carregador de quimoa ou uma quitandeira. Os leiteiros, que vinham de cidades vizinhas não apareceram com uma única lata para ser vendida. Os aguadeiros, segundo Theophilo (THEOPHILO, 2001, p. 133), "interromperam o serviço e os habitantes da cidade ficaram sem agua para beber, tendo apenas a agua de gasto, das cacimbas".

Deste modo, ao adentrar na construção da história política e jurídica da cidade de Fortaleza, durante o final do período do governo Accioly, tem-se a oportunidade de analisar as táticas construídas pelos populares, principalmente, de vendedores ambulantes na tentativa de desarticular a família Accioly, depô-la do poder, para assim acabar com o período de opressão sobre a arrecadação de impostos, aumento exacerbado do preço de produtos alimentícios e do monopólio da venda de carne.

O comércio informal de produtos alimentícios, de longa data, era importante para os moradores da cidade, pois, de modo geral, as pessoas sabiam que o comércio estabelecido no Mercado Público não era o suficiente para atender a demanda dos residentes. Por outro lado, além da acessibilidade que estes ambulantes prestavam aos fortalezenses, levando seus produtos até suas casas, os seus preços eram mais baixos, porque não pagavam impostos (CORBIN, 1987).

Tendo esta importância na capital cearense, sabiam que ausentando seus trabalhos durante o período, no qual, a cidade de Fortaleza foi sitiada pelos populares, os vendedores ambulantes desestruturariam a organização de fuga ou de manutenção do cativeiro dos Acciolys. Desta forma, é compreendido nesta pesquisa que as "maneiras de fazer" dos trabalhadores das ruas foram imprescindíveis para a manutenção do movimento político de aprisionamento e rendição do governo do Ceará.

Ao mesmo passo, entende-se, que, estes trabalhadores informais tinham uma compreensão concreta não só das estratégias gerenciadas pelo governo do Ceará para a normalização - e repressão - da vida e do comércio fortalezense, mais também do período em que a cidade permaneceu sitiada por estes. Neste momento de visibilidade, é possível apreender - e este é o interesse deste trabalho - o quanto os trabalhadores pobres da capital cearense estavam inseridos e articulados dentro da vida pública, adquirindo assim, meios de atuarem neste espaço de conflito, contribuindo para as mudanças do quadro social, econômico e político cearense. 
Segundo Theophilo (2001, p. 157), "o resto do dia 24 passou-se em festa. O trafego dos bondes foi restabelecido e Fortaleza entrou em sua vida normal”. Naquele dia, às nove horas da manhã, os Acciolys tinham se rendido e abandonado o Palácio do Governo.

Tendo como sucessor imediato o Sr. Coronel Carvalho Motta a presidência do Estado do Ceará, este tratou de reformular o governo, chamando novos secretários, e o intendente municipal. Para gerir o município, foi convocado o Sr. Dr. João Marinho e Andrade, "conceituado médico e homem de reconhecida probidade" (THEOPHILO, 2001, p. 177).

Durante o período de Marinho de Andrade, segundo Theophilo, "Fortaleza tinha outra feição". Os empregados da municipalidade receberam os vencimentos atrasados, os quais por meses não viam seus honorários; as ruas foram limpas com maior regularidade, o que não significa dizer que foram completamente aformoseadas; o Sindicato das Carnes foi extinto, findando o monopólio da venda de carne verde; o preço da carne baixou (GIRÃO, 1959).

Ocorreram mudanças significativas, é verdade. Mas para os trabalhadores das ruas os problemas permaneceram os mesmos. Seus "misteres" continuaram sendo vistos, pelo poder público, como nocivos para a população. Permaneceram na informalidade. Por outro lado, aquela repressão maciça, na qual os vendedores eram assassinados todos os dias, realmente, acabaram. Assim, compreende-se que os conflitos rearticulados pós-deposição de Accioly foram aqueles que fizeram parte da realidade dos trabalhadores de ruas desde a seca de 1877-79. Ou seja, eram práticas e disputas que faziam parte do universo social de vendedores e carregadores ambulantes (LEMENHE, 1991).

Trabalhar nas ruas de Fortaleza vendendo água, frutas, doces, carne ou carregando quimoas significava vivenciar o espaço da "marginalidade", "criminalidade", disputa de comercialização e venda de produtos de subsistência, do controle médico-sanitário, das leis e dos policiais. Experimentar o espaço da rua, para estas pessoas significava entrar em relação com estes conflitos, e isto era legítimo para aqueles populares (CERTEAU, 1994).

\section{CONSIDERAÇÕES FINAIS}

Entender a mecânica da vida pública da capital cearense exige forte reflexão sobre o papel das pessoas em busca de seus direitos. Independente dos discursos ou não da esfera política e institucional, os trabalhadores sabem o que é ser perseguido; impedido de trabalhar; agredido e ver companheiros sendo assassinados. Logo, não se faz necessário profunda discussão política pata entender aonde a falta de trato para com os cidadãos dói. 
Os vendedores de carne verde sabiam disso. No momento que se tornou oportuno não mais tolerar a pressão política, econômica e psicológica, foram às ruas e exigiram mudanças. A participação dos trabalhadores pobres fortalezenses foi vital para o fim do governo Accioly.

\section{THE PARTICIPATION OF GREEN MEAT HAWKERS IN THE ACCIOLY'S GOVERNMENT DEPOSITION (FORTALEZA OF THE BEGINNING OF THE XX CENTURY)}

\section{ABSTRACT}

This research aims to understand how poor informal workers, mainly sellers of fresh meat (green meat), contributed to the political movement that resulted in the fall of the Accioly government in the early part of the 20th century in the capital of Ceará. With the persecution against the informal work, the number of dissidents increased in the city, until, finally, within a collective composition, the multitude came to the streets and demanded the change of government. The article has a theoretical approach based on literature review, especially from the studies of Rodolpho Theophilo and Raimundo Girão.

Keywords: Hawker; political movement; informal work; government deposition.

\section{REFERÊNCIAS}

BAKHTIN, Mikhail M. A Cultura popular na Idade Média e no Renascimento: o contexto de François Rabelais. São Paulo: HUCITEC/UnB, 1993.

BARBOSA, Marta Emísia Jacinta. "Entre casas de palha e jardins: Fortaleza nas primeiras décadas do século XX”. In: Pesquisa em História. vol 1. São Paulo: Olho d'água, nov/1999, Pp. 153-172.

CERTEAU, Michel. A Invenção do Cotidiano: Artes de fazer. Petrópolis: Vozes, 1994.

CERUTTI, Simona. "A construção das categorias sociais". In: BOUTIER, Jean e JULIA, Dominique. Passados recompostos; campos e canteiros da história. Rio de Janeiro: Editora UFRJ: Editora FGV, 1998.

CORBIN, Alain. Saberes e odores: o olfato e o imaginário social nos séculos XVIII e XIX. São Paulo: Companhia das Letras, 1987.

FOUCAULT, Michel. Vigiar e punir. Rio de Janeiro: Vozes, 1999.

GIRÃO, Raimundo. Geografia Estética de Fortaleza. Fortaleza: Edições UFC, 1959.

LEMENHE, Maria Auxiliadora. As Razões de uma Cidade: conflito de hegemonias. Fortaleza: Stylus Comunicações, 1991. 
LINDENFELD, Jacqueline. "Palavras Rituais nos Mercados Urbanos na França". In: Revista Projeto História. São Paulo: EDUC, No 19, novembro/1999, Pp. 31-44.

MENEZES, Raimundo de. Coisas que o Tempo Levou... (Crônicas históricas da Fortaleza antiga). Fortaleza: Edésio Editor, 1938.

PONTE, Sebastião Rogério. Fortaleza Belle Époque: reformas urbanas e controle social (18601930). Fortaleza: Fundação Demócrito Rocha/Multigraf Editora Ltda., 1993.

THEOPHILO, Rodolpho. Libertação do Ceará: Queda da oligarquia Acioly. Edição fac-sim. Fortaleza: Fundação Waldemar Alcântara, 2001.

Trabalho enviado em 07 de fevereiro de 2019 Aceito em 13 de maio de 2020 